\title{
Molecular Imaging of ABCB1 and ABCG2 Inhibition at the Human Blood-Brain Barrier Using Elacridar and ${ }^{11} \mathrm{C}$-Erlotinib PET
}

\author{
Remy B. Verheijen ${ }^{1}$, Maqsood Yaqub $^{2}$, Emilia Sawicki ${ }^{1}$, Olaf van Tellingen ${ }^{3}$, Adriaan A. Lammertsma², \\ Bastiaan Nuijen $^{1}$, Jan H.M. Schellens ${ }^{4,5}$, Jos H. Beijnen ${ }^{1,5}$, Alwin D.R. Huitema ${ }^{1,6}$, N. Harry Hendrikse ${ }^{2,7}$, \\ and Neeltje Steeghs ${ }^{4}$
}

${ }^{I}$ Department of Pharmacy and Pharmacology, The Netherlands Cancer Institute-Antoni van Leeuwenhoek, Amsterdam, The Netherlands; ${ }^{2}$ Department of Radiology and Nuclear Medicine, VU University Medical Center, Amsterdam, The Netherlands; ${ }^{3}$ Department of Bio-Pharmacology/Mouse Cancer Clinic, The Netherlands Cancer Institute-Antoni van Leeuwenhoek, Amsterdam, The Netherlands; ${ }^{4}$ Department of Clinical Pharmacology and Medical Oncology, The Netherlands Cancer Institute-Antoni van Leeuwenhoek, Amsterdam, The Netherlands; ${ }^{5}$ Department of Pharmaceutical Sciences, Utrecht University, Utrecht, The Netherlands; ${ }^{6}$ Department of Clinical Pharmacy, Utrecht University Medical Center, Utrecht, The Netherlands; and ${ }^{7}$ Department of Clinical Pharmacology and Pharmacy, VU University Medical Center, Amsterdam, The Netherlands

Transporters such as $A B C B 1$ and $A B C G 2$ limit the exposure of several anticancer drugs to the brain, leading to suboptimal treatment in the central nervous system. The purpose of this study was to investigate the effects of the ABCB1 and ABCG2 inhibitor elacridar on brain uptake using ${ }^{11} \mathrm{C}$-erlotinib PET. Methods: Elacridar and cold erlotinib were administered orally to wildtype (WT) and $A b c b 1 a / b ; A b c g 2$ knockout mice. In addition, brain uptake was measured using ${ }^{11} \mathrm{C}$-erlotinib imaging and ex vivo scintillation counting in knockout and WT mice. Six patients with advanced solid tumors underwent ${ }^{11} \mathrm{C}$-erlotinib PET scans before and after a 1,000-mg dose of elacridar. ${ }^{11} \mathrm{C}$-erlotinib brain uptake was quantified by pharmacokinetic modeling using volume of distribution $\left(\mathrm{V}_{\mathrm{T}}\right)$ as the outcome parameter. In addition, ${ }^{15} \mathrm{O}-\mathrm{H}_{2} \mathrm{O}$ scans to measure cerebral blood flow were acquired before each ${ }^{11} \mathrm{C}$-erlotinib scan. Results: Brain uptake of ${ }^{11} \mathrm{C}$ erlotinib was 2.6-fold higher in Abcb1a/b;Abcg2 knockout mice than in WT mice, measured as percentage injected dose per gram of tissue $(P=0.01)$. In WT mice, the addition of elacridar (at systemic plasma concentrations of $\geq 200 \mathrm{ng} / \mathrm{mL}$ ) resulted in an increased brain concentration of erlotinib, without affecting erlotinib plasma concentration. In patients, the $\mathrm{V}_{\mathrm{T}}$ of ${ }^{11} \mathrm{C}$-erlotinib did not increase after intake of elacridar $(0.213 \pm 0.12$ vs. $0.205 \pm$ $0.07, P=0.91) .{ }^{15} \mathrm{O}-\mathrm{H}_{2} \mathrm{O}$ PET showed no significant changes in cerebral blood flow. Elacridar exposure in patients was $401 \pm$ $154 \mathrm{ng} / \mathrm{mL}$. No increase in $\mathrm{V}_{\mathrm{T}}$ with increased elacridar plasma exposure was found over the 271-619 ng/mL range. Conclusion: When Abcb1 and Abcg2 were disrupted in mice, brain uptake of ${ }^{11} \mathrm{C}$-erlotinib increased both at a tracer dose and at a pharmacologic dose. In patients, brain uptake of ${ }^{11} \mathrm{C}$-erlotinib was not higher after administration of elacridar. The more pronounced role that ABCG2 appears to play at the human bloodbrain barrier and the lower potency of elacridar to inhibit ABCG2 may be an explanation of these interspecies differences.

Received May 23, 2017; revision accepted Nov. 10, 2017. For correspondence or reprints contact: Remy B. Verheijen, Netherlands Cancer Institute, Louwesweg 6, Amsterdam, 1066EC, The Netherlands. E-mail: r.verheijen@nki.nl

Published online Nov. 24, 2017.

COPYRIGHT (C 2018 by the Society of Nuclear Medicine and Molecular Imaging.
Key Words: erlotinib; elacridar; blood-brain barrier; PET; molecular imaging

J Nucl Med 2018; 59:973-979

DOI: 10.2967/jnumed.117.195800

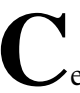

entral nervous system (CNS) metastases occur frequently in cancer patients and are known to result in a dismal prognosis. This can partly be explained by the pharmacokinetic properties of anticancer drugs, in particular their limited distribution into the brain.

The blood-brain barrier (BBB) is a major impediment to achieving pharmacologically active concentrations in the CNS $(1,2)$. A particular hurdle for CNS uptake of drugs is the expression of efflux transporters at the $\mathrm{BBB}$ endothelium, such as the adenosine triphosphatebinding cassette $(\mathrm{ABC})$ transporters $\mathrm{ABCB} 1$, known as P-glycoprotein, and $\mathrm{ABCG} 2$, known as breast cancer resistance protein (1-3). These efflux transporters restrict access to the CNS of even small lipophilic compounds, which would otherwise be able to penetrate cellular membranes by passive diffusion.

CNS tumors and metastases can disrupt the integrity of the BBB. However, this disruption is heterogeneous and occurs predominantly in the tumor core, where microvascular proliferation results in vessel leakiness $(1,4)$. Brain tissue adjacent to the tumor may therefore contain tumor cells that benefit from protection by an intact BBB. Hence, the CNS is regarded as a sanctuary site for anticancer drugs (5).

Elacridar is an inhibitor of ABCB1 (6) and ABCG2 (7). Numerous preclinical studies have shown that elacridar is able to enhance the brain penetration of substrate drugs, including erlotinib $(8,9)$. Erlotinib is an epidermal growth factor receptor inhibitor used in the treatment of advanced non-small cell lung cancer. Although non-small cell lung cancer frequently metastasizes to the brain, erlotinib exposure in the CNS is limited $(10,11)$, as it is a substrate of both ABCB1 and ABCG2 (12-14). ${ }^{11} \mathrm{C}$-erlotinib was developed as a radiotracer to noninvasively study the biodistribution 
and target binding of erlotinib in vivo $(15,16)$ and has been used to noninvasively study epidermal growth factor receptor mutations in tumor lesions of cancer patients $(17,18)$.

The purpose of our study was to assess whether ${ }^{11} \mathrm{C}$-erlotinib PET can quantify erlotinib uptake in the brain, as a readout of $\mathrm{ABCB} 1$ and $\mathrm{ABCG} 2$ inhibition at the BBB. First, experiments on mice were performed to establish the elacridar concentration needed to achieve Abcb1a/b and Abcg2 inhibition. Next, in vivo imaging in wild-type (WT) and $A b c b l a / b$ and $A b c g 2$ knockout mice was performed to establish the feasibility of monitoring drug transporter inhibition at the BBB using ${ }^{11} \mathrm{C}$-erlotinib PET. Finally, a clinical trial using ${ }^{11} \mathrm{C}$-erlotinib PET on cancer patients was performed to noninvasively study the effects of $\mathrm{ABCB} 1$ and ABCG2 inhibition on the brain penetration of erlotinib.

\section{MATERIALS AND METHODS}

\section{Preclinical Pharmacology}

Preclinical experiments were performed using female Friend Virus $\mathrm{B}$ mice, between 10 and $14 \mathrm{wk}$ of age, which were either WT or Abcb1a/lb;Abcg2 double-knockout.

Elacridar suspensions were prepared in vehicle solution $(1 \% \mathrm{~m} / \mathrm{v}$ hydroxypropyl methyl cellulose, $2 \% \mathrm{v} / \mathrm{v}$ polysorbate 80 in water) at concentrations of $1,2.5$, and $5 \mathrm{mg} / \mathrm{mL}$. An erlotinib suspension was prepared at $2 \mathrm{mg} / \mathrm{mL}$ in the same vehicle solution.

Nonfasted animals received $10 \mu \mathrm{L}$ of elacridar $(0,10,25$, or 50 $\mathrm{mg} / \mathrm{kg}$ ) per gram of body weight orally by gavage, followed $30 \mathrm{~min}$ later by $10 \mu \mathrm{L}$ of oral erlotinib $(20 \mathrm{mg} / \mathrm{kg})$ per gram. At $4 \mathrm{~h}$ after erlotinib dosing, blood was sampled by cardiac puncture. The animals were sacrificed, and brain tissue was collected. Brain tissue was homogenized in $3 \mathrm{~mL}$ of $1 \% \mathrm{v} / \mathrm{v}$ bovine serum albumin in water using a Fastprep 24 homogenizer (MPBio). Erlotinib and elacridar were quantified ex vivo in both plasma and brain homogenates by liquid chromatography tandem mass spectrometry. Each elacridar-treated group $(0,10,25$, and $50 \mathrm{mg} / \mathrm{kg})$ consisted of 4 mice. A group of Abcbla/lb; $A b c g 2$ knockout mice $(n=5)$ was used as a positive control.

\section{Preclinical Imaging}

Abcbla/b;Abcg2 WT and knockout mice ( $n=2$ for each group) were positioned in pairs in a double lutetium oxyorthosilicate/ $\mathrm{Lu} 1.8 \mathrm{Y} 0.2 \mathrm{SiO}$ (Ce) or lutetium oxyorthosilicate-lutetium yttrium oxyorthosilicate layer high-resolution research tomograph (Siemens/CTI) PET scanner (19). First, a transmission scan was acquired using a 740-MBq 2-dimensional fan-collimated ${ }^{137} \mathrm{Cs}$ (662 keV) moving point source (20). Next, a dynamic emission scan was acquired immediately after administration of $8-10 \mathrm{MBq}$ of ${ }^{11} \mathrm{C}$-erlotinib (specific activity $>18.5 \mathrm{GBq} / \mu \mathrm{mol})$ to each animal. Emission data were

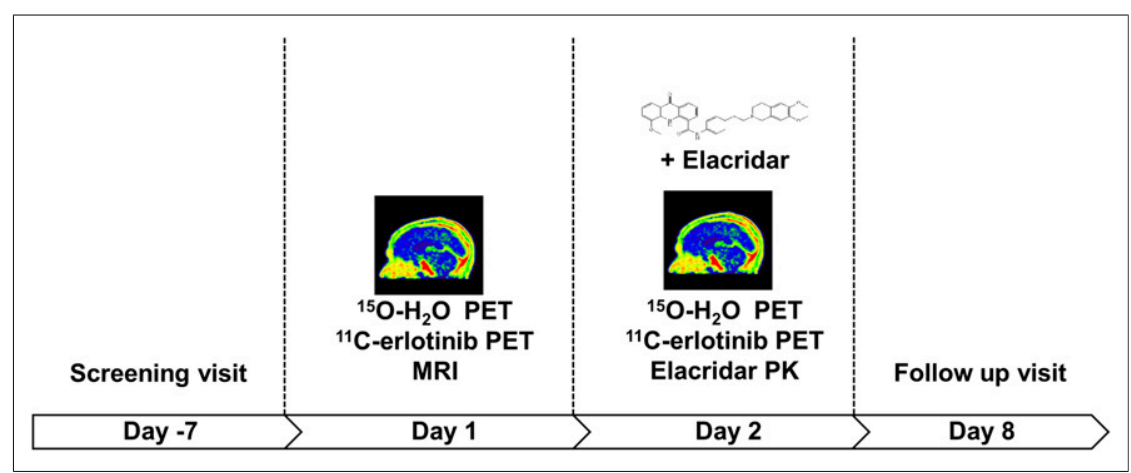

FIGURE 1. Schematic of clinical study design. acquired for $60 \mathrm{~min}$ in 3-dimensional (3D) list mode and rebinned into the following frame sequence: $4 \times 30,3 \times 60,2 \times 150$, and $4 \times$ 300 s. After corrections for decay, dead time, attenuation, randoms, and scatter, scans were reconstructed using a 3D ordinary Poisson ordered-subsets expectation maximization algorithm for mice (20). This resulted in images with an average spatial resolution of $3 \mathrm{~mm}$ in full width at half maximum (19).

After the scans, the mice were sacrificed. The brains were removed and weighed, and radioactivity was measured in a 1282 Compugamma CS (LKB Wallac) using five 10- $\mu \mathrm{L}$ aliquots of the injected formulation as an internal standard. The results were expressed as percentage injected dose per gram of brain tissue, corrected for decay to time of injection.

\section{Clinical Elacridar Formulation}

Elacridar hydrochloride was formulated as an (unpatented) tablet formulation, of which the pharmaceutical development was described earlier (21). These tablets have been shown to be well tolerated and resulted in relevant pharmacokinetic exposure in healthy volunteers (22).

\section{Clinical Study Design}

An overview of the clinical study design is presented in Figure 1. After a screening visit (day -7), patients were scheduled for ${ }^{11} \mathrm{C}$ erlotinib PET scans on 2 consecutive days (days 1 and 2). The ${ }^{11} \mathrm{C}$ erlotinib was given at a specific activity of more than $18.5 \mathrm{GBq} / \mu \mathrm{mol}$ without additional unlabeled erlotinib.

Because elacridar plasma concentrations have been shown to peak at 8-12 h after intake (22), patients took an oral 1,000-mg dose 8-12 h before the second scan. An MRI of the brain was acquired on day 1 with the purpose of excluding any brain metastases, because these might have compromised the function of the BBB. Each ${ }^{11} \mathrm{C}$-erlotinib scan was preceded by a ${ }^{15} \mathrm{O}-\mathrm{H}_{2} \mathrm{O}$ scan to assess possible effects of elacridar on cerebral blood flow. At the start and end of the second ${ }^{11} \mathrm{C}$-erlotinib scan, a venous blood sample was drawn to measure elacridar plasma concentrations (23).

On day 8 , a follow-up visit was scheduled. At each visit, patients were evaluated for safety, including assessment of adverse events, physical examination, performance status, blood pressure and heart rate measurements, and clinical laboratory tests. The incidence, severity, and start and end dates of all adverse events were recorded. Adverse events were graded according to the Common Terminology Criteria for Adverse Events (version 4.02).

\section{Patient Population}

Patients with advanced or metastatic solid tumors were eligible for enrollment if no standard therapy was available or if a tyrosine kinase inhibitor (if a substrate of $\mathrm{ABCB} 1$ and $\mathrm{ABCG} 2$ ) was the standard therapeutic option. Furthermore, patients had to be $18 \mathrm{y}$ of age with the following laboratory values: absolute neutrophil count of at least $1.5 \times 10^{9} / \mathrm{L}$, platelet count of at least $75 \times$ $109 / \mathrm{L}$, serum bilirubin no more than 2.0 times the upper limit of normal, aspartate amino transferase and alanine amino transferase levels no more than 2.5 times the upper limit of normal, serum creatinine level no more than 2.0 times the upper limit of normal, and creatinine clearance of at least $40 \mathrm{~mL} / \mathrm{min}$. Exclusion criteria were known brain metastases or previous treatment with CNS irradiation, as these could have compromised the function of the BBB. Patients discontinued any medication that induced, inhibited, or was a substrate for $\mathrm{ABCB} 1$ or $\mathrm{ABCG} 2$ at least 3 plasma elimination half-lives before the first PET scan. 


\section{Tracer Preparation and Scanning Procedure}

${ }^{11} \mathrm{C}$-erlotinib was synthesized and prepared as described previously (17). Scans were performed on a Gemini TF-64 PET/CT scanner (Philips), which is a high-performance, time-of-flight, fully 3D PET scanner together with a 16-slice Brilliance CT scanner. PET data were reconstructed using all appropriate corrections applied for normalization, dead time, decay, randoms, scatter, and attenuation. PET data were reconstructed using the 3D row-action maximum-likelihood algorithm with CT-based attenuation correction, at a final voxel size of $4 \times 4 \times$ $4 \mathrm{~mm}$ and a spatial resolution of 5-7 $\mathrm{mm}$ in full width at half maximum. First, a low-dose CT scan (50 mAs, without contrast) was performed for attenuation correction of the subsequent PET data. After the CT scan, $370 \mathrm{MBq}$ of ${ }^{15} \mathrm{O}-\mathrm{H}_{2} \mathrm{O}$ were injected intravenously, starting a 10-min emission scan in 3D mode. Next, after 10 min to allow for physical decay of ${ }^{15} \mathrm{O}, 370 \mathrm{MBq}$ of ${ }^{11} \mathrm{C}$-erlotinib were injected intravenously, simultaneously starting a 60 -min emission scan in $3 \mathrm{D}$ mode. The ${ }^{15} \mathrm{O}-$ $\mathrm{H}_{2} \mathrm{O}$ and ${ }^{11} \mathrm{C}$-erlotinib emission scans were acquired in list mode and sorted retrospectively into 26 frames $(1 \times 10,8 \times 5,4 \times 10,2 \times 15,3 \times$ $20,2 \times 30$, and $6 \times 60 \mathrm{~s})$ and 36 frames $(1 \times 10,8 \times 5,4 \times 10,2 \times 15$, $3 \times 20,2 \times 30,6 \times 60,4 \times 150,4 \times 300$, and $2 \times 600$ s), respectively. No corrections for patient motion or respiratory motion were applied.

All patients received an indwelling radial artery cannula for arterial blood sampling (17). In addition, a venous cannula was inserted for tracer injection and sampling of venous blood. The arterial input function was measured using online continuous blood sampling (at 300 $\mathrm{mL} / \mathrm{h}$ for the first $5 \mathrm{~min}$ and $150 \mathrm{~mL} / \mathrm{h}$ for the next $15 \mathrm{~min}$ ) (24). At discrete time points $(5,10,20,40$, and $60 \mathrm{~min}$ after injection), manual samples were obtained for online calibration of the measured wholeblood input function, determination of plasma-to-whole-blood ratios, and measurement of metabolite fractions. Plasma analysis of ${ }^{11} \mathrm{C}$ erlotinib and polar radioactive metabolites were counted using a Wizard $1480 \gamma$-counter (Perkin Elmer).

\section{PET Data Analysis}

To investigate whole-brain uptake, 3D regions of interest (average size, $612 \mathrm{~mL}$ ) were defined manually around the whole brain, as seen on CT and MRI scans, and projected onto the dynamic PET scan, thereby generating ${ }^{11} \mathrm{C}$-erlotinib time-activity curves.
Pharmacokinetic modeling was performed using in-house software, developed within the Matlab (The MathWorks Inc.) environment. Data were fitted with single-tissue, 2-tissue reversible, and 2-tissue irreversible metabolite-corrected plasma input models. The optimal plasma input model was determined on the basis of visual analysis of the time-activity curves, the Akaike criteria, and the sensitivity of the kinetic parameters. For the reversible models, the volume of distribution, $\mathrm{V}_{\mathrm{T}}$ (dimensionless quantity), was used as the outcome parameter describing erlotinib uptake in tissue, as described previously $(17,25)$.

\section{Study Conduct and Registration}

All animal experiments were approved by the animal ethics committee of The Netherlands Cancer Institute and were performed according to institutional guidelines and in compliance with Dutch legislation.

The clinical trial was conducted in accordance with the Declaration of Helsinki and approved by the medical ethics review committee of each of the participating medical centers. The trial was registered in the EUdraCT clinical trial database (2014-000281-21) and Netherlands trial registry (NTR4780). All patients provided written informed consent before enrollment.

\section{RESULTS}

\section{Preclinical Pharmacology}

Increasing the dose of elacridar resulted in an increased elacridar plasma concentration (Fig. 2, left panel). At $4 \mathrm{~h}$ after dosing, the plasma elacridar concentrations were $216 \pm 46,275 \pm$ 60 , and $455 \pm 44 \mathrm{ng} / \mathrm{mL}$ for the 10,25 , and $50 \mathrm{mg} / \mathrm{kg}$ dose, respectively. The erlotinib plasma concentration was 1,020 \pm 350 in WT mice receiving elacridar vehicle and 2,610 \pm 710 , $2,610 \pm 290$, and $1,900 \pm 830 \mathrm{ng} / \mathrm{mL}$ at the 10,25 , and $50 \mathrm{mg} / \mathrm{kg}$ elacridar dose. The erlotinib plasma concentration in knockout mice was $1,700 \pm 120 \mathrm{ng} / \mathrm{mL}$.

Erlotinib brain-to-plasma ratios were $0.25 \pm 0.06,0.31 \pm 0.05$, and $0.37 \pm 0.04$ for the increasing doses of elacridar (Fig. 2, right panel). The ratio for untreated WT mice was $0.09 \pm 0.01$. Each dose was a significantly higher ratio than vehicle $(P<0.002$ for each dose, independent-sample $t$ tests). The Abcbla/b;Abcg2 knockout mice had a brainto-plasma ratio of $0.45 \pm 0.02$.
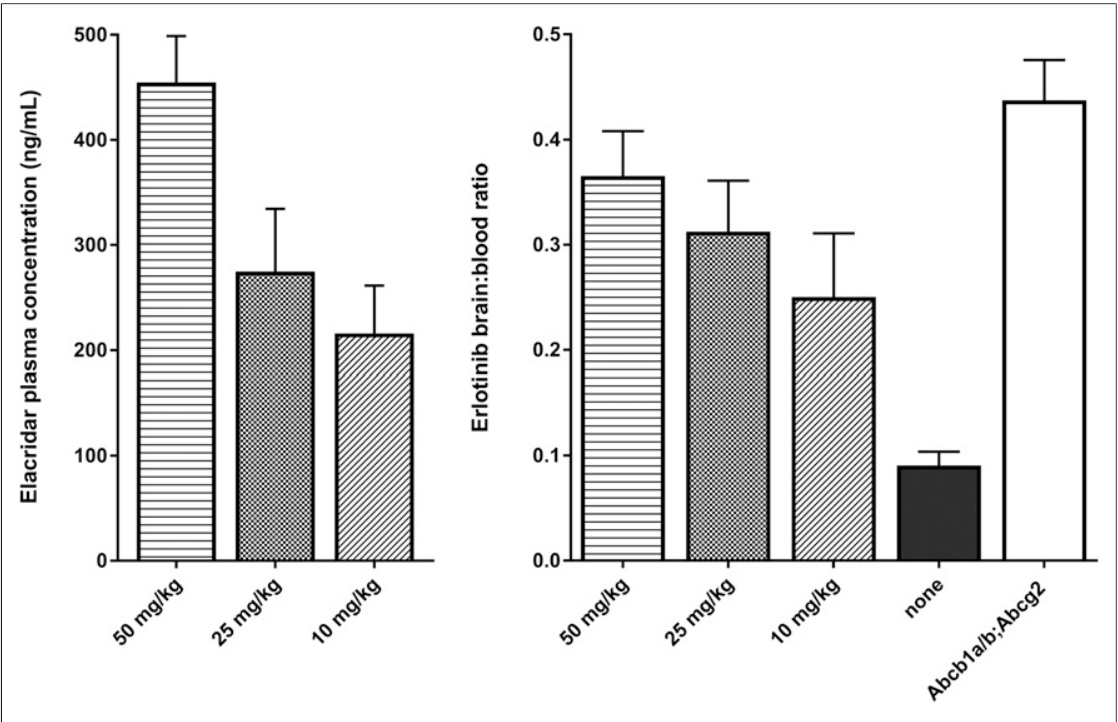

FIGURE 2. (Left) Elacridar plasma concentrations in $\mathrm{ng} / \mathrm{mL}$ for increasing oral dose of elacridar $(0,10,25$, and $50 \mathrm{mg} / \mathrm{kg})$. (Right) Erlotinib brain-to-plasma ratios at same increasing doses of elacridar in WT mice $(n=4)$. Group of $A b c b 1 a / b ; A b c g 2$ knockout mice was used as positive controls $(n=5)$.

\section{Preclinical Imaging}

Representative summed images of a WT and a Abcbla/b;Abcg2 knockout mouse are shown in Figure 3, left panel. ${ }^{11} \mathrm{C}$ erlotinib PET scans showed increased cerebral uptake in knockout mice compared with WT mice. The ${ }^{11} \mathrm{C}$-erlotinib percentage injected dose per gram of brain tissue was determined ex vivo in knockout and WT mice. ${ }^{11} \mathrm{C}$-erlotinib brain uptake was increased 2.6-fold in the knockout mice compared with the WT mice $(P=0.01$, independent-sample $t$ test), as shown in Figure 3, right panel.

\section{Clinical Trial Results}

From September 2014 to March 2015, 7 patients gave written informed consent to participate. One patient dropped out before the first administration of ${ }^{11} \mathrm{C}$-erlotinib because of unsuccessful placement of the 


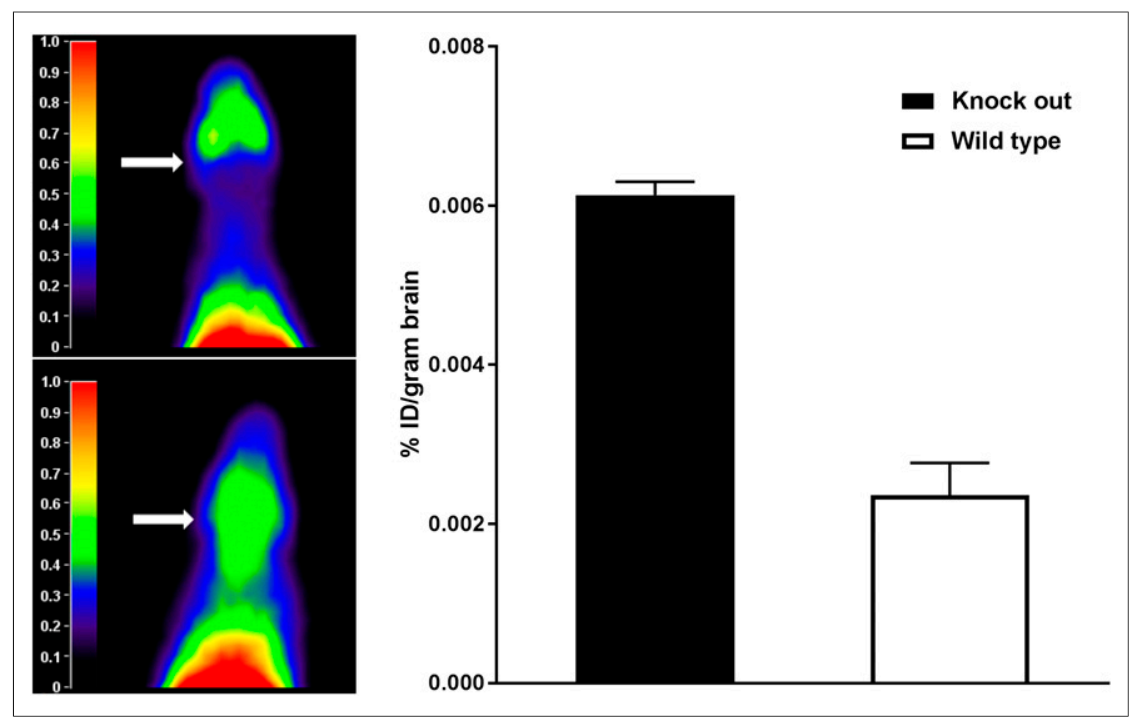

FIGURE 3. (Left) Representative summation images of $A b c b 1 a / b ; A b c g 2$ knockout mouse (bottom) and WT mouse (top). Arrows indicate brain. (Right) ${ }^{11} \mathrm{C}$-erlotinib percentage injected dose (\%ID) per gram of brain determined ex vivo in knockout and WT mice. Erlotinib brain penetration was significantly higher in knockout mice ( $n=2$ per group).

arterial catheter. The 6 remaining patients all underwent the entire protocol. Because of problems with the arterial sampling, no input function was available for one patient and the peak uptake was missed in the first scan of another patient. PET data from the remaining 4 patients were available for evaluation, in both scans. After analysis of the data of these patients, enrollment was terminated because of lack of effect.

The evaluable patients were all male, had a mean $( \pm$ SD) age of $57 \pm 8 \mathrm{y}$, and weighed $81 \pm 14 \mathrm{~kg}$. Four patients had a gastrointestinal stromal tumor and one had advanced colorectal cancer. In the patients with gastrointestinal stromal tumor, imatinib treatment was interrupted $3 \mathrm{~d}$ before inclusion and restarted after the trial. The colorectal cancer patient did not receive active treatment. All patients had undergone gastrointestinal surgery before enrollment.
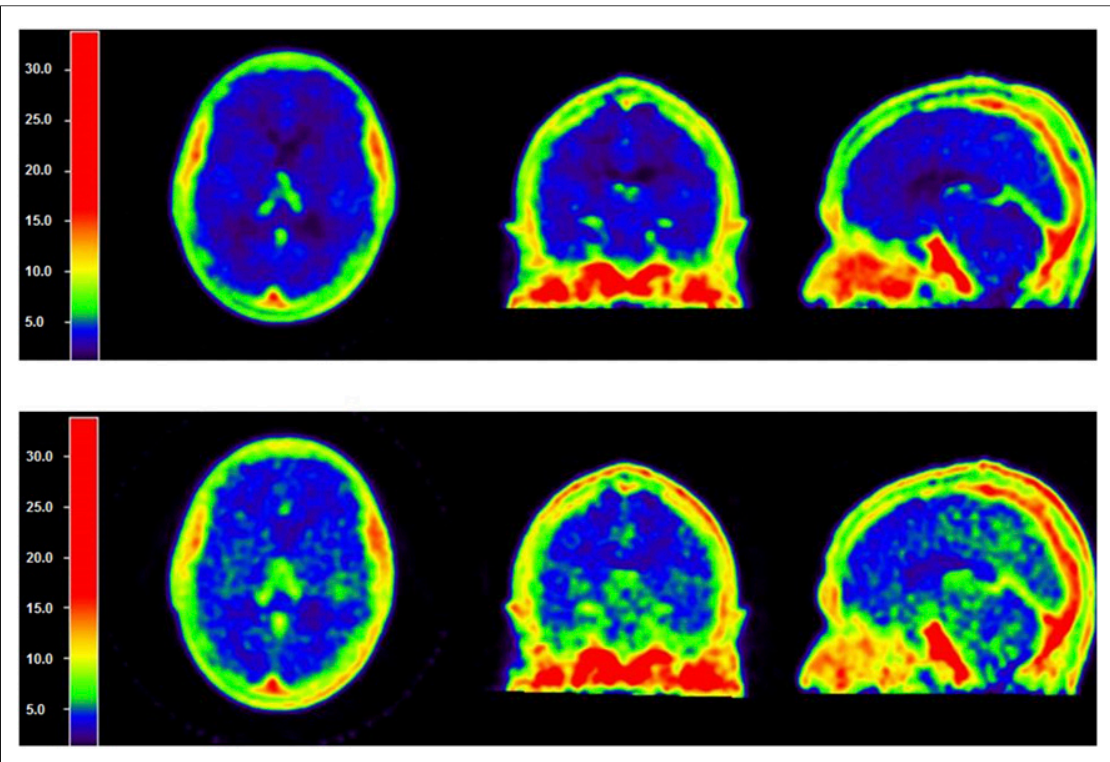

FIGURE 4. ${ }^{11} \mathrm{C}$-erlotinib PET before (top) and after (bottom) elacridar for subject 4.
None of the patients experienced adverse events related to the tracer dose of erlotinib. Two patients experienced adverse events related to elacridar. These were both grade 1 and included headache and taste alteration. No new safety signals were observed compared with previous trials with elacridar (26-28). Other adverse events observed from the moment informed consent was given until the last follow-up visits, considered to be unrelated to elacridar, included hypertension (grade 3), syncope (grade 3), dyspepsia, anxiety, nausea, and sneezing (all grade 1).

\section{Clinical Imaging}

Averaged ${ }^{11} \mathrm{C}$-erlotinib PET images (5$60 \mathrm{~min}$, corrected for ${ }^{11} \mathrm{C}$-erlotinib dose) before and after a 1,000-mg dose of elacridar for the subject with the largest increase in $\mathrm{V}_{\mathrm{T}}$ are shown in Figure 4. ${ }^{11} \mathrm{C}$-erlotinib activity was markedly lower in the brain than in the surrounding tissues. The ${ }^{11} \mathrm{C}$ erlotinib dose did not significantly differ between the first and second scans, at $363 \pm 37$ versus $333 \pm$ $55 \mathrm{MBq}(P=0.28$, paired-sample $t$ test $)$. Moreover, no differences were observed in specific activity before $(55.68 \mathrm{GBq} / \mu \mathrm{mol})$ and after elacridar $(50.65 \mathrm{GBq} / \mu \mathrm{mol})$, resulting in comparable erlotinib doses of 2.54 and $2.61 \mu \mathrm{g}$, respectively.

The optimal plasma input model for fitting ${ }^{11} \mathrm{C}$-erlotinib data in the brain is the single-tissue model ( $89 \%$ preference) followed by the 2 -tissue reversible model (11\%), according to the Akaike criterion. Kinetic parameters for the single-tissue model are given in Table 1, and all of the following analyses were performed using this model. However, the fitted $V_{T}$ was highly correlated between the single- and 2-tissue reversible model $\left(r^{2}=0.9979\right)$. The $\mathrm{V}_{\mathrm{T}}$ of ${ }^{11} \mathrm{C}$-erlotinib did not increase after administration of elacridar $(0.213 \pm 0.123$ vs. $0.205 \pm 0.071$; $P=0.91$, paired-sample $t$ test). ${ }^{11} \mathrm{C}$-erlotinib whole-brain activity curves as SUV versus time for patients before and after a 1,000-mg dose of elacridar are shown in Figure 5. The metabolism of erlotinib was unaffected by elacridar. The curves for the percentage parent erlotinib versus time during the scan before and after the elacridar dose are provided in Supplemental Figure 1 (supplemental materials are available at http://jnm.snmjournals.org).

Cerebral blood flow was unaffected by administration of elacridar: ${ }^{15} \mathrm{O}-\mathrm{H}_{2} \mathrm{O} \quad K_{1}$ was $0.48 \pm 0.10$ before and $0.44 \pm 0.13$ after the $1,000-\mathrm{mg}$ dose of elacridar $(P=$ 0.21 , paired-sample $t$ test). For patients evaluable in both scans, mean elacridar plasma concentrations on the day of the PET scan (the averages of the samples at the start and end of the scan) were $401 \pm$ $154 \mathrm{ng} / \mathrm{mL}$. The ratio of $\mathrm{V}_{\mathrm{T}}$ (after and before elacridar) versus elacridar plasma concentration is plotted in Figure 6. No 
TABLE 1

$K_{1}, K_{2}$, and $\mathrm{V}_{\mathrm{T}}$ of Brain ${ }^{11} \mathrm{C}$-Erlotinib Before and After Elacridar Administration in Cancer Patients $(n=5)$

\begin{tabular}{|c|c|c|c|c|c|c|c|}
\hline \multirow[b]{2}{*}{ Patient no. } & \multicolumn{3}{|c|}{${ }^{11} \mathrm{C}$-erlotinib before elacridar } & \multicolumn{3}{|c|}{${ }^{11} \mathrm{C}$-erlotinib after elacridar } & \multirow[b]{2}{*}{$\mathrm{V}_{\mathrm{T}}$ ratio } \\
\hline & $K_{1}$ & $K_{2}$ & $\mathrm{~V}_{\mathrm{T}}$ & $K_{1}$ & $K_{2}$ & $\mathrm{~V}_{\mathrm{T}}$ & \\
\hline 1 & 0.012 & 0.030 & 0.395 & 0.011 & 0.036 & 0.312 & 0.790 \\
\hline 2 & 0.015 & 0.090 & 0.167 & 0.013 & 0.066 & 0.198 & 1.186 \\
\hline 3 & - $^{*}$ & 一 $^{*}$ & - $^{*}$ & 0.014 & 0.080 & 0.179 & - $^{*}$ \\
\hline 4 & 0.010 & 0.060 & 0.160 & 0.017 & 0.076 & 0.221 & 1.381 \\
\hline 5 & 0.12 & 0.100 & 0.128 & 0.014 & 0.123 & 0.116 & 0.906 \\
\hline Mean \pm SD & $0.012 \pm 0.002$ & $0.070 \pm 0.032$ & $0.213 \pm 0.123$ & $0.014 \pm 0.002$ & $0.076 \pm 0.031$ & $0.205 \pm 0.071$ & $1.066 \pm 0.268$ \\
\hline
\end{tabular}

*Data were excluded because peak uptake was missed during first scan.

Ratio is based on patients evaluable in both scans.

increase in $\mathrm{V}_{\mathrm{T}}$ ratio with higher elacridar plasma concentration was found over the $271-619 \mathrm{ng} / \mathrm{mL}$ range.

\section{DISCUSSION}

It was hypothesized that inhibition of ABCB1 and ABCG2 by elacridar should result in increased erlotinib brain exposure in mice and in humans. In mice, we showed increased brain uptake at both a pharmacologic (Fig. 2) and a tracer (Fig. 3) erlotinib dose, in accordance with previous studies on mice and nonhuman primates $(8,12,29)$. However, these preclinical data could not be reproduced in humans (Table 1; Figs. 4 and 5).

To our knowledge, this was the first study performed on human brain using ${ }^{11} \mathrm{C}$-erlotinb with dynamic images in combination with metabolite-corrected plasma input function. The optimal pharmacokinetic model for use in the brain was the single-tissue-compartment model, according to the Akaike criterion. However, the differences in the estimated $V_{T}$ between the 2-tissue-compartment model and the single-tissue-compartment model were small. Furthermore, it is expected that the 2-tissue model will perform better for regions with higher specific uptake. However, as uptake is expected to be low in patients without lesions in the brain, the single-tissue model is the preferred model to be used with ${ }^{11} \mathrm{C}$-erlotinib in this setting.

Previously the test-retest variability for ${ }^{11} \mathrm{C}$-erlotinib $\mathrm{V}_{\mathrm{T}}$ in tumor lesions was quantified at $12 \%$. Variability in $\mathrm{V}_{\mathrm{T}}$ was relatively higher in this study than in previous trials $(17,25)$, probably because the $\mathrm{V}_{\mathrm{T}}(<0.5)$ values for erlotinib $\mathrm{V}_{\mathrm{T}}$ in the brain were lower than in previously explored tumor images.

In patients, no effect of $A B C B 1$ or ABCG2 inhibition on $V_{T}$ and no relationship between erlotinib $V_{T}$ ratio and elacridar exposure were seen, even though plasma concentrations of as high as $600 \mathrm{ng} / \mathrm{mL}$ were measured (Fig. 6). This finding could be due to several factors: insufficient elacridar exposure, nonlinear pharmacokinetics of erlotinib, or interspecies differences in the BBB.

Low free plasma concentrations of the inhibitor and nonlinearity of transporter inhibition could be suggested as possible explanations for the lack of effect (30). It is unlikely that this

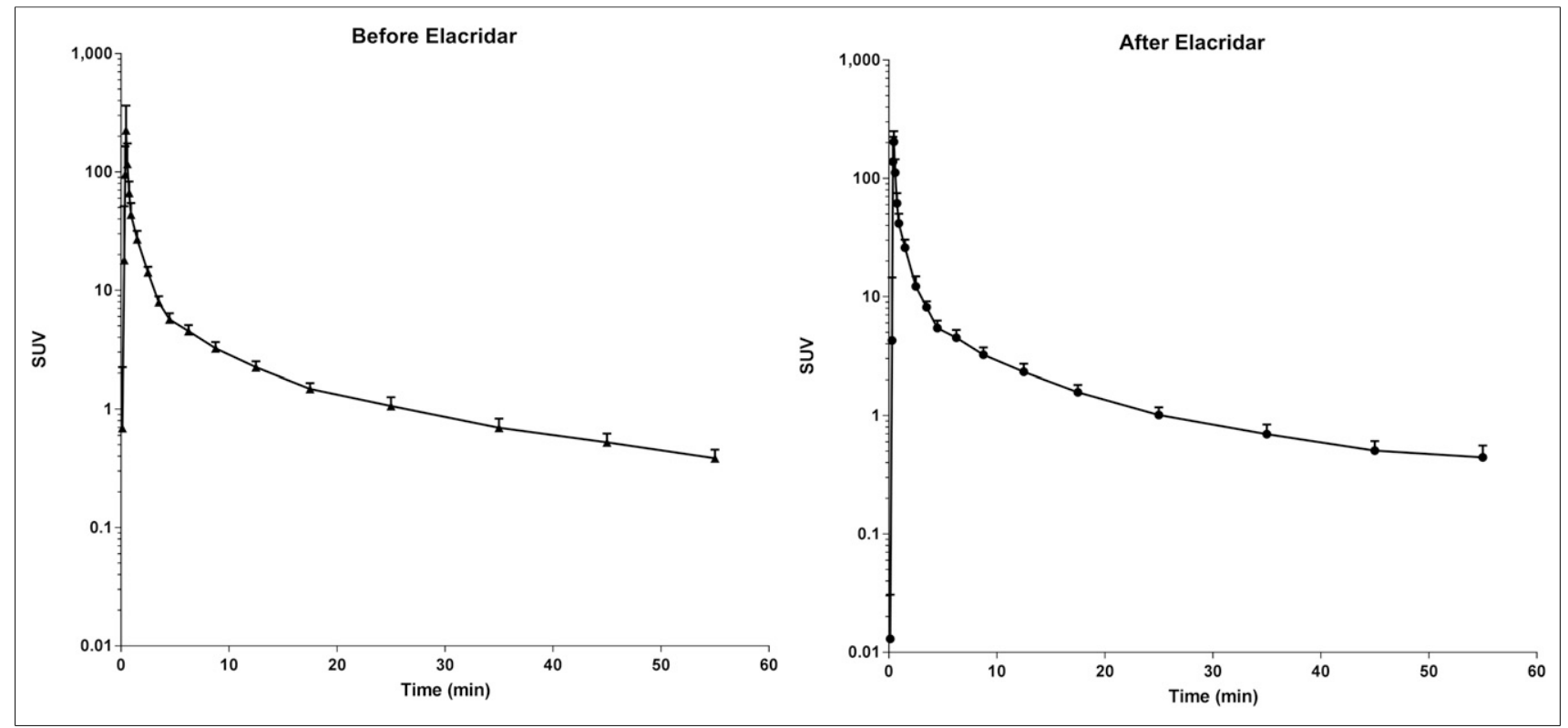

FIGURE 5. ${ }^{11} \mathrm{C}$-erlotinib whole-brain activity as SUV vs. time (in minutes) for patients before and after administration of elacridar $(n=5)$. 


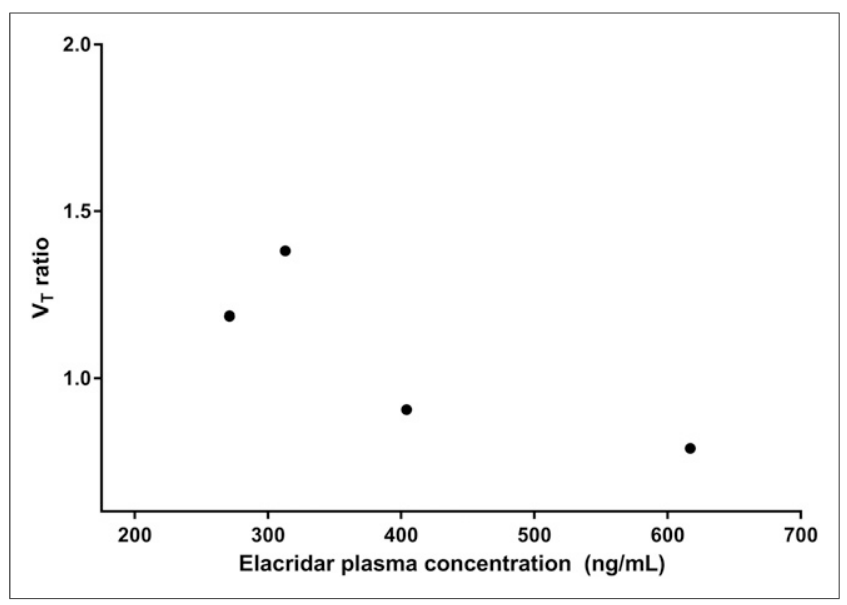

FIGURE 6. ${ }^{11} \mathrm{C}$-erlotinib brain $\mathrm{V}_{\mathrm{T}}$ ratio vs. elacridar exposure $(n=5)$.

possibility applies to the combination of elacridar and erlotinib. Previously, Kuntner et al. performed a dose-finding study of elacridar using ${ }^{11} \mathrm{C}$-verapamil imaging as readout (31). Elacridar was found to increase brain uptake at concentrations at or above 200 $\mathrm{ng} / \mathrm{mL}$. Similarly, our preclinical data show an increased erlotinib brain exposure at elacridar plasma concentrations of $200-400 \mathrm{ng} / \mathrm{mL}$ (Fig. 2), and the plasma levels of elacridar in our clinical trial were similar, if not higher. Moreover, no trend toward an increasing $V_{T}$ ratio with increasing elacridar concentration was seen over the 94$619 \mathrm{ng} / \mathrm{mL}$ range. A species difference in free drug concentrations is also unlikely because protein binding of erlotinib and its major metabolite desmethyl erlotinib is similar in mice and humans (95\% vs. $92 \%$ for erlotinib and $73 \%$ vs. $90 \%$ for desmethyl erlotinib) (32).

This seems to eliminate limited elacridar exposure as an explanation for the lack of increased brain exposure in the clinical study. Yet, inhibition by elacridar resulted in a 3.5 -fold increase in ${ }^{11} \mathrm{C}$-erlotinib brain $\mathrm{V}_{\mathrm{T}}$ in primates (29). However, these results were achieved at an extremely high elacridar plasma concentration of maximally $10.0 \pm 1.5 \mu \mathrm{g} / \mathrm{mL}$, using an intravenous infusion. Although it is possible that such high elacridar levels in humans may also cause a better brain uptake of erlotinib, these levels will be hard to achieve via oral dosing given the unbeneficial pharmaceutical properties of elacridar. The concentrations observed in the current trial $(401 \pm 154 \mathrm{ng} / \mathrm{mL}$, Fig. 6) were already higher than most of the peak serum concentrations in previous clinical trials (140-434 ng/mL) (22,26-28,33).

This clinical study used a tracer dose of erlotinib. Therefore, nonlinear pharmacokinetics of erlotinib could be an explanation for the absence of an effect on $\mathrm{V}_{\mathrm{T}}$ (as it could be argued that a higher dose of erlotinib would have shown an increase in brain uptake). However, given the fact that we showed increased brain uptake at both a pharmacologic (Fig. 2) and a tracer (Fig. 3) dose of erlotinib in preclinical studies, this explanation is unlikely.

Although a previous study of ${ }^{11} \mathrm{C}$-erlotinib on mice (8) suggested that erlotinib pharmacokinetics were nonlinear and that erlotinib itself may be an inhibitor of ABCB1 and ABCG2, inhibition of these transporters by erlotinib is unlikely at tracer doses and probably also at pharmacologic doses. This possibility also conflicts with our preclinical experiments and with clinical observations that erlotinib cerebral spinal fluid concentrations are markedly lower than levels in plasma $(10,11)$.

A high dose of erlotinib did result in an increased erlotinib brain $\mathrm{V}_{\mathrm{T}}$ in primates, but this effect was markedly smaller than that of elacridar (only a 1.7-fold increase compared with 3.5-fold). In a previous clinical ${ }^{11} \mathrm{C}$-erlotinib study, addition of cold erlotinib resulted in markedly lower $\mathrm{V}_{\mathrm{T}}$ in tumor lesions of cancer patients (18), supporting the choice not to add a pharmacologic erlotinib dose in this trial.

The above leave interspecies differences as the most likely explanation for the discrepancy between the preclinical and clinical results. First, interspecies differences in drug transporter efficiency have been shown for various substrates even when corrected for protein expression levels (34). Second, Uchida et al. quantified absolute protein levels of $\mathrm{ABCB} 1$ and $\mathrm{ABCG} 2$ in mice and human brain tissue (35). ABCG2 expression was found to be 1.8-fold higher and $\mathrm{ABCB} 1$ expression was 2.33-fold lower in humans than in mice. If $\mathrm{ABCG} 2$ is thus more prominent in the human $\mathrm{BBB}$ or if human $\mathrm{ABCG} 2$ is an efficient transporter of erlotinib, insufficient inhibition of ABCG2 could explain the lack of effect. This hypothesis is supported by reports suggesting that elacridar inhibits $A B C B 1$ at $50-100 \mathrm{nM}$ but that $250 \mathrm{nM}$ is required for inhibition of $\mathrm{ABCG} 2(6,7)$, albeit it is likely that the inhibitory potency will be different for each substrate.

Third, ABCG2 is known to compensate for ABCB1 inhibition for double substrates (35), as has also been shown for erlotinib in preclinical experiments (12). Here, the largest gain in the erlotinib brain accumulation was seen when ABCB1 was absent, with only a moderate further increase when both $\mathrm{ABCB} 1$ and $\mathrm{ABCG} 2$ were absent. Therefore, the increase of erlotinib in mice that occurs with elacridar is caused predominantly by the inhibition of ABCB1 by elacridar. This finding is also in line with human studies using ${ }^{11} \mathrm{C}$-verapamil (a substrate for $\mathrm{ABCB} 1$ but not ABCG2 (36,37)) showing statistically significant, albeit small, increases in brain uptake in ABCB1 and ABCG2 inhibition. Besides species differences in substrate affinities and transporter expression, other unknown factors may contribute to the observed differences. However, on the basis of these observations, we advise that future clinical trials aiming to increase brain exposure by administration of elacridar should try to avoid using strong ABCG2 substrates and focus primarily on $\mathrm{ABCB} 1$ or weak ABCG2 substrates.

\section{CONCLUSION}

To our knowledge, this was the first study investigating the effect of BBB transporter inhibition on ${ }^{11} \mathrm{C}$-erlotinib in the clinical setting. No increased brain $V_{T}$ was found in patients treated with elacridar. The more pronounced role that ABCG2 appears to play at the human $\mathrm{BBB}$ and the lower potency of elacridar to inhibit ABCG2 may be an explanation fpr these interspecies differences.

\section{DISCLOSURE}

This research was funded by a personal grant from the Netherlands Cancer Institute to Neeltje Steeghs. Olaf van Tellingen is coinventor on a patent application (Bunt and Van Tellingen, 2014; US 20140235631A1) dealing with development of an improved oral formulation for elacridar. No other potential conflict of interest relevant to this article was reported. 


\section{ACKNOWLEDGMENT}

We thank all patients for their participation in the clinical trial.

\section{REFERENCES}

1. van Tellingen O, Yetkin-Arik B, De Gooijer MC, Wesseling P, Wurdinger T, De Vries HE. Overcoming the blood-brain tumor barrier for effective glioblastoma treatment. Drug Resist Updat. 2015;19:1-12.

2. Milojkovic Kerklaan B, van Tellingen O, Huitema ADR, et al. Strategies to target drugs to gliomas and CNS metastases of solid tumors. J Neurol. 2016;263:428-440.

3. Deeken JF, Löscher W. The blood-brain barrier and cancer: transporters, treatment, and Trojan horses. Clin Cancer Res. 2007;13:1663-1674.

4. Lockman PR, Mittapalli RK, Taskar KS, et al. Heterogeneous blood-tumor barrier permeability determines drug efficacy in experimental brain metastases of breast cancer. Clin Cancer Res. 2010;16:5664-5678.

5. Gainor JF, Ou SH, Logan J, Borges LF, Shaw AT. The central nervous system as a sanctuary site in ALK-positive non-small-cell lung cancer. J Thorac Oncol. 2013;8:1570-1573.

6. Hyafil F, Vergely C, Du Vignaud P, Grand-Perret T. In vitro and in vivo reversal of multidrug resistance by GF120918, an acridonecarboxamide derivative. Cancer Res. 1993;53:4595-4602.

7. de Bruin M, Miyake K, Litman T, Robey R, Bates SE. Reversal of resistance by GF120918 in cell lines expressing the ABC half-transporter, MXR. Cancer Lett. 1999; 146:117-126.

8. Traxl A, Wanek T, Mairinger S, et al. Breast cancer resistance protein and Pglycoprotein influence in vivo disposition of ${ }^{11} \mathrm{C}$-erlotinib. J Nucl Med. 2015;56: 1930-1936.

9. Sane R, Mittapalli RK, Elmquist WF. Development and evaluation of a novel microemulsion formulation of elacridar to improve its bioavailability. J Pharm Sci. 2013;102:1343-1354.

10. Broniscer A, Panetta JC, O'Shaughnessy M, et al. Plasma and cerebrospinal fluid pharmacokinetics of erlotinib and its active metabolite OSI-420. Clin Cancer Res. 2007; 13:1511-1515.

11. Togashi Y, Masago K, Masuda S, et al. Cerebrospinal fluid concentration of gefitinib and erlotinib in patients with non-small cell lung cancer. Cancer Chemother Pharmacol. 2012;70:399-405.

12. de Vries NA, Buckle T, Zhao J, Beijnen JH, Schellens JHM, Van Tellingen O. Restricted brain penetration of the tyrosine kinase inhibitor erlotinib due to the drug transporters P-gp and BCRP. Invest New Drugs. 2012;30:443-449.

13. Kodaira H, Kusuhara H, Fujita T, Ushiki J, Fuse E, Sugiyama Y. Quantitative evaluation of the impact of active efflux by p-glycoprotein and breast cancer resistance protein at the blood-brain barrier on the predictability of the unbound concentrations of drugs in the brain using cerebrospinal fluid concentration as a surrogate. J Pharmacol Exp Ther. 2011;339:935-944.

14. Kodaira H, Kusuhara H, Ushiki J, Fuse E, Sugiyama Y. Kinetic analysis of the cooperation of P-glycoprotein (P-gp/Abcb1) and breast cancer resistance protein (Bcrp/Abcg2) in limiting the brain and testis penetration of erlotinib, flavopiridol and mitoxantrone. J Pharmacol Exp Ther. 2010;333:788-796.

15. Abourbeh G, Itamar B, Salnikov O, Beltsov S, Mishani E. Identifying erlotinibsensitive non-small cell lung carcinoma tumors in mice using $\left[{ }^{11} \mathrm{C}\right]$ erlotinib PET. EJNMMI Res. 2015;5:4

16. Memon AA, Jakobsen S, Dagnaes-Hansen F, Sorensen BS, Keiding S, Nexo E. Positron emission tomography (PET) imaging with [ $\left.{ }^{11} \mathrm{C}\right]$-labeled erlotinib: a micro-PET study on mice with lung tumor xenografts. Cancer Res. 2009;69: 873-878.

17. Bahce I, Smit EF, Lubberink M, et al. Development of $\left[{ }^{11} \mathrm{C}\right]$ erlotinib positron emission tomography for in vivo evaluation of EGF receptor mutational status. Clin Cancer Res. 2013;19:183-193.

18. Bahce I, Yaqub M, Errami H, et al. Effects of erlotinib therapy on $\left[{ }^{11} \mathrm{C}\right]$ erlotinib uptake in EGFR mutated, advanced NSCLC. EJNMMI Res. 2016;6:10.
19. de Jong HWAM, van Velden FHP, Kloet RW, Buijs FL, Boellaard R, Lammertsma AA. Performance evaluation of the ECAT HRRT: an LSO-LYSO double layer high resolution, high sensitivity scanner. Phys Med Biol. 2007;52: 1505-1526.

20. van Velden FHP, Kloet RW, van Berckel BNM, Lammertsma AA, Boellaard R. Accuracy of 3-dimensional reconstruction algorithms for the high-resolution research tomograph. J Nucl Med. 2009;50:72-80.

21. Sawicki E, Schellens JHM, Beijnen JH, Nuijen B. Pharmaceutical development of an amorphous solid dispersion formulation of elacridar hydrochloride for proof-of-concept clinical studies. Drug Dev Ind Pharm. 2017;43: 584-594.

22. Sawicki E, Verheijen RB, Huitema ADR, et al. Clinical pharmacokinetics of an amorphous solid dispersion tablet of elacridar. Drug Deliv Transl Res. 2017;7: $125-131$.

23. Stokvis E, Rosing H, Causon R, Schellens J, Beijnen J. Quantitative analysis of the P-glycoprotein inhibitor elacridar (GF120918) in human and dog plasma using liquid chromatography with tandem mass spectrometric detection. $J$ Mass Spectrom. 2004;39:1122-1130.

24. Boellaard R, Van Lingen A, Van Balen SCM, Hoving BG, Lammertsma AA. Characteristics of a new fully programmable blood sampling device for monitoring blood radioactivity during PET. Eur J Nucl Med. 2001;28:81-89.

25. Yaqub M, Bahce I, Voorhoeve C, Schuit RC, Windhorst AD, Hoekstra OS, et al. Quantitative and simplified analysis of ${ }^{11} \mathrm{C}$-erlotinib studies. J Nucl Med. 2016;57: $861-866$.

26. Kemper EM, Van Zandbergen AE, Cleypool C, et al. Increased penetration of paclitaxel into the brain by inhibition of P-glycoprotein. Clin Cancer Res. 2003;9: 2849-2855.

27. Malingré MM, Beijnen JH, Rosing H, et al. Co-administration of GF120918 significantly increases the systemic exposure to oral paclitaxel in cancer patients. Br J Cancer. 2001;84:42-47.

28. Kruijtzer CMF, Beijnen JH, Rosing H, et al. Increased oral bioavailability of topotecan in combination with the breast cancer resistance protein and P-glycoprotein inhibitor GF120918. J Clin Oncol. 2002;20:2943-2950.

29. Tournier N, Goutal S, Auvity S, et al. Strategies to inhibit ABCB1- and ABCG2mediated efflux transport of erlotinib at the blood-brain barrier: a PET study on nonhuman primates. J Nucl Med. 2017;58:117-122.

30. Kalvass JC, Polli JW, Bourdet DL, et al. Why clinical modulation of efflux transport at the human blood-brain barrier is unlikely: the ITC evidence-based position. Clin Pharmacol Ther. 2013;94:80-94.

31. Kuntner C, Bankstahl JP, Bankstahl M, et al. Dose-response assessment of tariquidar and elacridar and regional quantification of P-glycoprotein inhibition at the rat blood-brain barrier using (R)-[ $\left.{ }^{11} \mathrm{C}\right]$ verapamil PET. Eur J Nucl Med Mol Imaging. 2010;37:942-953.

32. European Public Assessment Report: Tarceva. European Medicines Agency website. http://www.ema.europa.eu/docs/en_GB/document_library/EPAR_-_Product_ Information/human/000618/WC500033994.pdf. Updated July 2, 2010. Accessed January 19, 2018.

33. Kuppens IELM, Witteveen EO, Jewell RC, et al. A phase I, randomized, openlabel, parallel-cohort, dose-finding study of elacridar (GF120918) and oral topotecan in cancer patients. Clin Cancer Res. 2007;13:3276-3285.

34. Katoh M, Suzuyama N, Takeuchi T, Yoshitomi S, Asahi S, Yokoi T. Kinetic analyses for species differences in P-glycoprotein-mediated drug transport. J Pharm Sci. 2006;95:2673-2683.

35. Uchida Y, Ohtsuki S, Katsukura Y, et al. Quantitative targeted absolute proteomics of human blood-brain barrier transporters and receptors. J Neurochem. 2011;117:333-345.

36. Agarwal S, Elmquist WF. Insight into the cooperation of P-glycoprotein (ABCB1) and breast cancer resistance protein $(\mathrm{ABCG} 2)$ at the blood-brain barrier: a case study examining sorafenib efflux clearance. Mol Pharm. 2012;9:678-684.

37. Römermann K, Wanek T, Bankstahl M, et al. (R)- $\left[{ }^{11} \mathrm{C}\right]$ verapamil is selectively transported by murine and human P-glycoprotein at the blood-brain barrier, and not by MRP1 and BCRP. Nucl Med Biol. 2013;40:873-878. 